\title{
Novel Low Cost Biosorbents of Phenolic Compounds from Olive Mill Wastewaters ${ }^{\dagger}$
}

\author{
Nikoletta Solomakou and Athanasia M. Goula * \\ Department of Food Science and Technology, School of Agriculture, Aristotle University of Thessaloniki, P.O. \\ Box 235, 54124 Thessaloniki, Greece; nsolomak@gmail.com \\ * Correspondence: athgou@agro.auth.gr \\ + Presented at the 1st International Electronic Conference on Applied Sciences, 10-30 November 2020; \\ Available online: https://asec2020.sciforum.net/.
}

Published: 10 November 2020

\begin{abstract}
Olive oil is one of the most widely used oils in the world with economic importance for many countries. Olive oil extraction generates large amounts of solid (cake) and liquid waste (olive mill wastewater, OMW), that pose a chronic environmental problem due to their disposal of the produced wastes on the landfill and water recipients. Thus, the research community is in search of techniques, individually or in combination, in order to detoxify waste. The common treatment methods belong to a one-dimension waste treatment approach, which is depollution. A practical way to overcome the financial obstacle of depollution is to develop treatment schemes that combine depollution with recovery of valuable ingredients, such as phenolics. The toxicity of this waste is mainly due to the high concentration of phenolic compounds, which, however, have strong antioxidant activity, turning OMW into an economical raw material for the recovery of bioactive compounds. Adsorption is generally considered to be the most effective and low-cost method for the removal of phenolics. So far, few studies have been carried out using sorbents for the removal of phenolics from OMW. However, the relatively high initial cost and the need for a costly regeneration system render common sorbents less economically viable. Thus, many researchers have focused their efforts on optimizing adsorption process by development of novel, low-cost adsorbents with high adsorptive capacity, originating from food industry byproducts (biosorbents). The objective of this work is to provide a comprehensive summary of the biosorbents used for OMW management.
\end{abstract}

Keywords: olive mill wastewater; food wastes; adsorption; phenolic compounds; biosorbents; polyphenols recovery

\section{Introduction}

Olive oil is one of the most widely used oils in the world with economic importance for many countries. This agro-industrial activity generates large amounts of wastes such as solid (cake) and liquid (olive mill wastewater, OMW), that pose a severe environmental pollution.

There are two ways of olive oil extraction: traditional pressing and centrifugation systems, which are used over the last decades. As for centrifugation systems there are two different types the two-phase and three-phase systems. At present, more and more modern olive mills use the continuous three-phase extraction process system, which generates two streams of waste: a solid waste ( $\sim 30 \%$ of raw material weight) called "orujo" or "olive cake," and a liquid waste $(50 \%$ of raw material weight) called "olive mill wastewater" (OMW) [1]. 


\section{OMW Composition}

In Mediterranean countries, more than 2.4 million tons of olives are produced every year, which corresponds to $95 \%$ of total world production. Due to the fact that $90 \%$ of this amount is destined for olive oil production, the proper treatment of OMW is crucial [2]. As a waste, OMW consists a dark liquid, with an intense odor, high turbidity, high organic content, and relatively low $\mathrm{pH}$ (Figure 1).
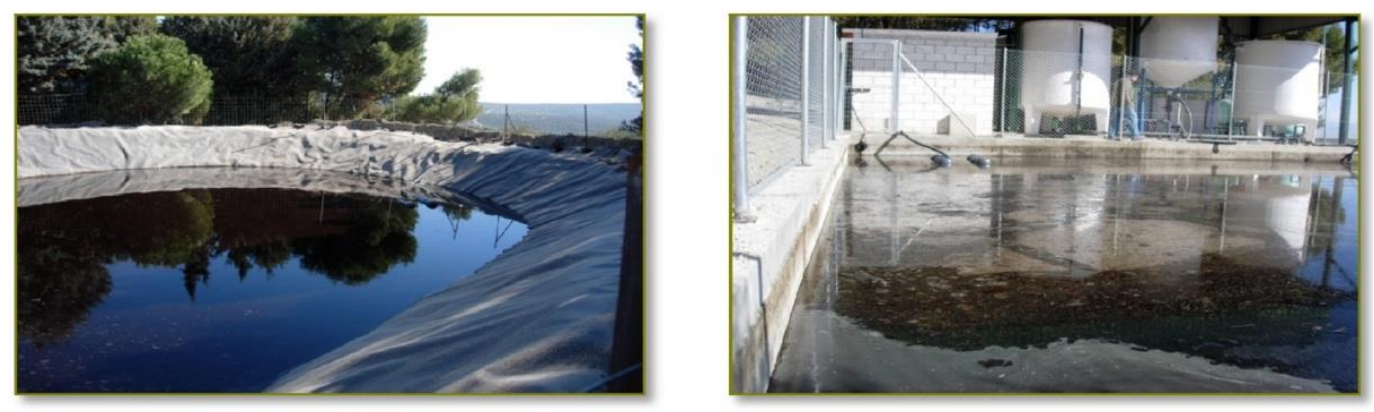

Figure 1. Olive mill wastewater.

OMW is considered to be a great environmental hazard when not properly treated, as it contains high concentrations of organic compounds such as organic acids, lipids, alcohols and polyphenols (Table 1).

According to literature, more than 30 phenolic compounds have been detected in OMW, the total concentration of which ranges from 0.5 to $24.0 \mathrm{~g} / \mathrm{L}$, depending on the processing system used for olive oil extraction [3]. Research on the phenolic profile of OMW shows that flavonoids represent $45-65 \%$ of the total phenolic content, while flavanols and proanthocyanidins consist the main flavonoid subgroups [4]. In addition, hydroxytyrosol appears to be the most dominant phenolic compound in OMW, representing approximately $55-70 \%$ of total phenolic content [5].

Table 1. Characteristics of OMW.

\begin{tabular}{ccc}
\hline Characteristic & OMW & Reference \\
\hline $\mathrm{pH}$ & $2.2-5.9$ & {$[6,7]$} \\
Total carbon (\%) & $2.0-3.3$ & {$[8]$} \\
Organic matter (\%) & $57.2-62.1$ & {$[9]$} \\
Total nitrogen (\%) & 0.63 & {$[7,10]$} \\
Ash (\%) & 1.0 & {$[10]$} \\
Lipids (\%) & $0.03-4.25$ & {$[7,10]$} \\
Total sugars (\%) & $1.50-12.22$ & {$[9]$} \\
Total proteins (\%) & $3.43-7.26$ & {$[11]$} \\
Total phenols (\%) & $0.63-5.45$ & {$[7]$} \\
\hline
\end{tabular}

\section{OMW Treatment}

There are several ways for OMW management (depollution), which can be divided into three categories: physical and physicochemical processes (thermal methods, flocculation, adsorption), biological processes (aerobic and anaerobic) and combination of both. All aforementioned methods present the same financial obstacle, as the size of most olive mills is relatively small. Waste management schemes that combine depollution with the extraction of valuable compounds is a possible way of overcoming this financial burden. Consequently, the profit from the extraction of these compounds could compensate for the cost of waste treatment. In order to fractionate valuable compounds derived from OMW, processing methods have been employed in recent approaches. Phenolic compounds, dietary fibers and squalene are considered to be the most popular constituents isolated from OMW. 


\section{Adsorption}

The recovery of OMW polyphenols has been mainly studied on small scale and many methods have been used, either individually or in combination (membrane separation, extraction, adsorption, and chromatographic procedures). Out of all these methods, physical adsorption is thought to be the most economical and effective. The efficiency of the adsorption and desorption methods influence significantly the ability of such waste treatment applications to create profit margins. To date, only a few studies have been conducted on the recovery of OMW phenolic compounds using a variety of sorbent materials (Figure 2).

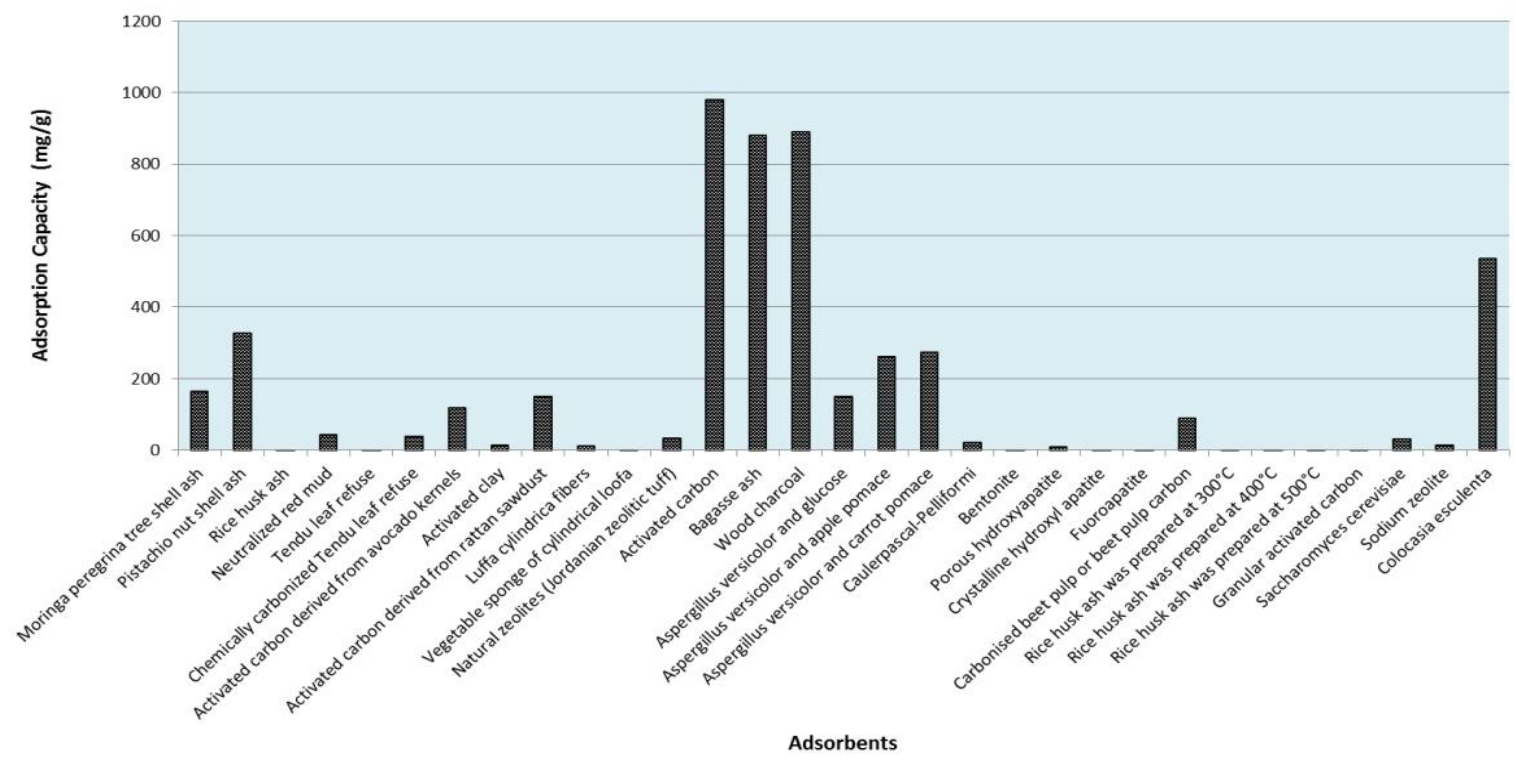

Figure 2. Adsorption capacities of various adsorbents for phenolic compounds [12].

\section{Biosorbents}

Although some of the sorbents mentioned above achieve sufficient adsorption capacities, the high initial and regeneration costs render these materials less economically viable options. Therefore, numerous studies have been focused on the optimization of adsorption methods utilizing innovative, low-cost, and highly efficient adsorbents generated from food industry wastes (biosorbents) (Table 2). Although most of these sorbents (biosorbents) constitute food industry by-products or agricultural wastes, they offer many advantages. The most important are their low cost, their availability and the fact that they can be easily regenerated.

Table 2. Bioabsorbent materials for the selective adsorption of waste compounds.

\begin{tabular}{|c|c|c|}
\hline Biosorbent & Waste & Reference \\
\hline Azolla & Polyphenols from olive mill wastewater & [13] \\
\hline Banana peel & $\begin{array}{l}\text { Phenolic compounds from olive mill } \\
\text { wastewaters }\end{array}$ & [14] \\
\hline Nutshells & $\begin{array}{l}\text { Phenolic compounds from aqueous } \\
\text { solutions }\end{array}$ & [15] \\
\hline Oil palm kernel shell & $\begin{array}{l}\text { Organic and inorganic pollutants in } \\
\text { palm oil mill effluent (POME) }\end{array}$ & [16] \\
\hline Olive pomace & $\begin{array}{l}\text { Total phenols from olive mill } \\
\text { wastewater }\end{array}$ & [17] \\
\hline Olive stone and pulp & $\begin{array}{l}\text { Total phenols from olive mill } \\
\text { wastewater }\end{array}$ & [6] \\
\hline $\begin{array}{l}\text { Pomegranate peel and } \\
\text { orange juice by-product }\end{array}$ & $\begin{array}{l}\text { Phenolic compounds from olive mill } \\
\text { wastewaters }\end{array}$ & [18] \\
\hline
\end{tabular}




\begin{tabular}{lcc}
\hline Biosorbent & Waste & Reference \\
\hline Pomegranate seeds & $\begin{array}{c}\text { Phenolic compounds from olive mill } \\
\text { wastewaters }\end{array}$ & {$[19]$} \\
Wheat bran & $\begin{array}{c}\text { Phenolic compounds from olive mill } \\
\text { wheat husk }\end{array}$ & {$[20]$} \\
Whewaters & {$[21]$} \\
\hline
\end{tabular}

Such adsorbent materials are banana peels, olive pomace, wheat bran etc. Stasinakis et al. [17] investigated total phenol removal efficiency from OMW by several types of treated olive pomace (dried olive pomace, dried and solvent extracted olive pomace and dried, solvent extracted and incompletely combusted olive pomace). Goud et al. [15] investigated the adsorption of phenols 2 through the treatment of nutshells, whereas Achak et al. [14] used banana peel as a low-cost solution biosorbent for removing phenolic compounds from OMW yielding a 88\% removal. The efficiency of pomegranate peels and orange juice by-product in removing the total OMW phenolics was investigated by Ververi and Goula [18] reporting a 93.1 and $89.5 \%$ removal, respectively. However, in general, little work has been done on the adsorption of phenolic compounds from OMW using novel low cost biosorbents.

\section{Conclusions}

Olive oil extraction generates a variety of by-products. Most of these wastes are valorized as animal feed or discharged in the environment, posing a severe threat for the environment. The potential use of these by-products for the recovery of bioactive and health-promoting ingredients, such as polyphenols, is remarkable. On the other hand, coffee production and brewing processes also generate high amounts of by-products, such as spent coffee grounds, which can be utilized for the adsorption of bioactive compounds from OMW. In this way, two by-products of the food industry can be utilized with the ultimate purpose of incorporating the extracted bioactive compounds as functional ingredients in novel food products. However, further studies are needed in order to fully evaluate the potential of these by-products for the extraction of phenolic compounds and investigate the optimum conditions of these procedures.

Author Contributions: Conceptualization, N.S. and A.M.G.; methodology, A.M.G.; software, N.S.; validation, N.S.; formal analysis, N.S.; investigation, N.S. and A.M.G.; resources, A.M.G.; data curation, N.S.; writing - original draft preparation, N.S.; writing - review and editing, A.M.G.; visualization, N.S. and A.M.G.; supervision, A.M.G.; project administration, A.M.G.; funding acquisition, A.M.G. All authors have read and agreed to the published version of the manuscript.

Conflicts of Interest: The authors declare no conflict of interest.

\section{References}

1. Tsagaraki, E.V.; Lazarides, H.N.; Petrotos, K. Olive mill wastewater treatment. In Utilization of By-Products and Treatment of Waste in the Food Industry; Oreopoulou, V., Russ, W., Eds.; Springer Science: New York, USA, 2007; pp. 133-157.

2. Paraskeva, C.A.; Papadakis, V.G.; Tsarouchi, E.; Kanellopoulou, D.G.; Koutsoukos, P.G. Membrane Processing for Olive Mill Wastewater Fractionation. Desalination 2007, 213, 218-229, doi:10.1016/j.desal.2006.04.087.

3. Russo, C. A new membrane process for the selective fractionation and total recovery of polyphenols, water and organic substances from vegetation waters (VW). J. Membr. Sci. 2007, 288, 239-246 doi:10.1016/j.memsci.2006.11.020.

4. El-Abbassi, A.; Kiai, H.; Hafidi, A.; García-Payo, M.; Khayet, M. Treatment of olive mill wastewater by membrane distillation using polytetrafluoroethylene membranes. Sep. Purif. Technol. 2012, 98, 55-61, doi:10.1016/j.seppur.2012.06.026.

5. El-Abbassi, A.; Kiai, H.; Hafidi, A. Phenolic profile and antioxidant activities of olive mill wastewater. Food Chem. 2012, 132, 406-412, doi:10.1016/j.foodchem.2011.11.013. 
6. Galiatsatou, P.; Metaxas, M.; Arapoglou, D.; Kasselouri-Rigopoulou, V. Treatment of olive mill waste water with activated carbons from agricultural by-products. Waste Manage. 2002, 22, 803-812, doi:10.1016/s0956-053x(02)00055-7.

7. Dermeche, S.; Nadour, M.; Larroche, C.; Moulti-Mati, F.; Michaud, P. Olive mill wastes: Biochemical characterizations and valorization strategies. Process Biochem. 2013, 48, 1532-1552, doi:10.1016/j.procbio.2013.07.010

8. Garcia-Castello, E.; Cassano, A.; Criscuoli, A.; Conidi, C.; Drioli, E. Recovery and concentration of polyphenols from olive mill wastewaters by integrated membrane system. Water Res. 2010, 44, 3883-3892, doi:10.1016/j.watres.2010.05.005.

9. Vlyssides, A.G.; Loizides, M.; Karlis, P.K. Integrated strategic approach for reusing olive oil extraction by-products. J. Clean. Prod. 2004, 12, 603-611, doi:10.1016/S0959-6526(03)00078-7.

10. Di Giovacchino, L.; Prezioso, S. Utilization of olive mill by-products. In Recent Advances in Olive Industry, Proceedings of Olive BIOTEQ, 2006; pp. 379-389.

11. Alburquerque, J.A.; Gonzalvez, J.; Garcia, D.; Cegarra, J. Agrochemical characterisation of "alperujo," a solid by-product of the two phase centrifugation method for olive oil extraction. Bioresour. Technol. 2004, 91, 195-200, doi:10.1016/S0960-8524(03)00177-9.

12. Bazrafshan, E.; Amirian, P.; Mahvi, A.H.; Ansari-Moghaddam, A. Application of adsorption process for phenolic compounds removal from aqueous environments: A systematic review. Glob. NEST J. 2016, 18, 146-63, doi:10.30955/gnj.001709.

13. Ena, A.; Pintucci, C.; Carlozzi, P. The Recovery of Polyphenols from Olive Mill Waste using two Adsorbing Vegetable Matrices. J. Biotechnol. 2012, 157, 573-577, doi:10.1016/j.jbiotec.2011.06.027.

14. Achak, M.; Hafidi, A.; Ouazzani, N.; Sayadi, S.; Mandi, L. Low cost biosorbent "banana peel" for the removal of phenolic compounds from olive mill wastewater: Kinetic and equilibrium studies. J. Hazard. Mater. 2009, 166, 117-125, doi:10.1016/j.jhazmat.2008.11.036.

15. Goud, V.V.; Mohanty, K.; Rao, M.S.; Jayakumar, N.S. Phenol removal from aqueous solutions by tamarind nutshell activated carbon: Batch and column studies. Chem. Eng. Technol. 2005, 28, 814-821, doi:10.1002/ceat.200500013.

16. Hayawin, Z.N.; Ibrahim, M.F.; Faizah, J.N.; Ropandi, M.; Astimar, A.A.; Noorshamsiana, A.W.; Abd-Aziz, S. Palm oil mill final discharge treatment by a continuous adsorption system using oil palm kernel shell activated carbon produced from two-in-one carbonization activation reactor system. J. Water Process Eng. 2020, 36, 101262, doi:10.1016/j.jwpe.2020.101262.

17. Stasinakis, A.S.; Elia, I.; Petalas, A.V.; Halvadakis, C.P. Removal of Total Phenols from Olive-Mill Wastewater using an Agricultural By-Product, Olive Pomace. J. Hazard. Mater. 2008, 160, 408-413, doi:10.1016/j.jhazmat.2008.03.012.

18. Ververi, M.; Goula, A.M. Pomegranate peel and orange juice by-product as new biosorbents of phenolic compounds from olive mill wastewaters. Chem. Eng. Process. 2019, 138, 86-96, doi:10.1016/j.cep.2019.03.010.

19. Papaoikonomou, L.; Labanaris, K.; Kaderides, K.; Goula, A.M. Adsorption-desorption of phenolic compounds from olive mill wastewater using a novel low-cost biosorbent. Environ. Sci. Pollut. Res. 2019, 1-15, doi:10.1007/s11356-019-07277-2.

20. Achak, M.; Hafidi, A.; Mandi, L.; Ouazzani, N. Removal of phenolic compounds from olive mill wastewater by adsorption onto wheat bran. Desalin. Water Treat. 2014, 52, 2875-2885, doi:10.1080/19443994.2013.819166.

21. Devaanshi, J.; Pranita, J. Deportation of toxic phenol from aqueous system by wheat husk. Int. J. Plant Anim. Environ. Sci. 2014, 4, 58-64.

22. Blinová, L.; Sirotiak, M.; Bartošová, A.; Soldán, M. Utilization of waste from coffee production. Res. Pap. Fac. Mater. Sci. Technol. Slovak Univ. Technol. 2017, 25, 91-101, doi:10.1515/rput-2017-0011.

Publisher's Note: MDPI stays neutral with regard to jurisdictional claims in published maps and institutional affiliations.

(C) 2020 by the authors. Submitted for possible open access publication under the terms and conditions of the Creative Commons Attribution (CC BY) license (http://creativecommons.org/licenses/by/4.0/). 
